\title{
Factors Affecting Life Satisfaction of Employees under Financial Threat
}

Dr. Rizwan Qaisar Danish

Rabia Shahid ${ }^{1}$

Hafiz Fawad Ali

Received 2018-12-20

Accepted 2019-01-09

Published 2019-01-10

Keywords

Economic Hardship, Prospective

Anxiety,

Work-related Stress,

Life satisfaction,

Financial Threat

How to cite?

Danish, D. R., Shabid, R., \& Ali, $H$.

F. (2019). Factors Affecting life

Satisfaction of Employees under Financial

Threat. SEISENSE Journal of

Management, 2(1), 85-98.

bttps:/ / doi.org/10.33215/sjom.v2i1.82

Copyright (c) 2019 The Author(s)

(cc) BY
Hailey College of Commerce, University of the Punjab Lahore Pakistan

Hailey College of Commerce, University of the Punjab Lahore Pakistan

Institute of Business Administration, University of the Punjab Lahore Pakistan

\footnotetext{
${ }^{1}$ Corresponding Author's email address: rabiashahid092@gmail.com
} 


\section{Introduction}

In the early 1900s, work satisfaction received the attention of researchers from various disciplines like HRM (Godard, 2004), OB (Locke, 2009) and Psychology (Gilbreth, 1918). General satisfaction has two main elements: job and life satisfaction (Boardman, 1985). Life satisfaction is the level in which people feel positively or negatively about their lives (Niharika \& Kiran, 2014a). Life satisfaction is an important and widely researched area in the field of organizational psychology (Spector, 1997). Employees whose lives are more satisfied are generally more committed with their work, reveal low absenteeism and more efficient in their work (Lease, 1998). An individual who has a higher level of job satisfaction hold positive emotions about the life, while individuals who have negative emotions about the life, they are not satisfied with their job (Niharika \& Kiran, 2014b).

Several studies found that employees are less satisfied than entrepreneurs (Millan et al., 2013; Schjoedt, 2009). Increase in risk of depression leads to low level of satisfaction of life (Swami et al., 2007). Life satisfaction is the idea that demonstrates the entire personal satisfaction and is a basic component of "positive mental health" (Hwang \& Kim, 2008).

Past studies have frequently focused to link various attitude with behavior directly but not tested process or mechanism in banks. The banking sector is very critical and backbone of each economy. In Pakistan, the banking sector is growing day by day. According to state bank report, the banking sector has expanded by $8.3 \%$ in 2017 . But, it is observed that the life of employees is disturbed due to work overload, long working hours, stressful working conditions, increasing debts which cause anxiety, burnout, and many other psychological and physical problems. So, the purpose of this study to determine what are the factors affecting the life satisfaction of employees in the banking sector under financial threat.

This study fills the gap by analyzing the impact of work stress, economic conditions and behavioral outcomes on life satisfaction. The current study may also advantageous for managers and government to understand the consequences of economic hardship and anxiety among employees through financial threat. So, it is said that money may help to improve an individual's economic condition, with respect to, enhance their physical and emotional prosperity (Kahenman \& Deaton, 2010). Finally, diversity in debt level is another approach to modifying an individual's monetary circumstances in this manner bringing down tension. It is greater or expanding singular obligation that had been archived alongside the mental misery they produce (Greenglass, et al., 2013) either purposed modifications in an individual's debt might bring about lower trouble. So, individuals might be inspired to alter their economic conditions in increasing their assets or diminish their outlays and obligations. So, this is rational that intention to alter their economical conduct is an important role in decreasing in psychological (fear, misgiving, anxiety), and intellectual (disasters, stress, fanatical contemplations) encounters related with debt and economic hardship.

\section{Research Questions:}

- What is the relationship between Economic Hardship and Life Satisfaction?

- What is the relationship between Prospective Anxiety and Life Satisfaction?

- What is the relationship between Work-related Stress and Life Satisfaction?

- What is the relationship between Financial Threat and Life Satisfaction?

- Can financial threat mediate the relationship between Economic Hardship and Life Satisfaction?

- Can financial threat mediate the relationship between Prospective Anxiety and Life Satisfaction?

- Can financial threat mediate the relationship between Work-related stress and Life Satisfaction?

\section{Research Objectives}


- To explore the relationship between Economic Hardship and Life Satisfaction.

- To explore the relationship between Prospective Anxiety and Life Satisfaction.

- To explore the relationship between Work-related stress and Life Satisfaction.

- To explore the relationship between Financial Threat and Life Satisfaction.

- To know that Financial Threat mediates the relationship between Economic Hardship and Life Satisfaction.

- To know that Financial Threat mediates the relationship between Prospective Anxiety and Life Satisfaction.

- To know that Financial Threat mediates the relationship between Work-related Stress and Life Satisfaction.

\section{Literature Review}

Ayala-Nunes, Jimenezi, Jesus, and Hidalgo (2018) confirmed that predictors of psychological distress are significantly related to economic hardship and a negative indicator of social support (network dysfunctionality). This distress leads to low level of life satisfaction. Miles, Szwedo, and Allen (2018) found that sometimes career satisfaction may decrease due to anxiety. However, anxious individuals may achieve career satisfaction because of positive coping and functional competence skills. Schmitt, Aknin, Axsen, and Shwom (2017) investigated whether perceived ecological threat can be avoided by a change in lifestyle and enhance wellbeing and they found positive evidence. Past studies have shown that cognitive estimates of financial hardship are strongly connected with the arrangement of financially destitute teenagers. (e.g, Hunt, Cladwell \& Assari , 2015 ; Lee et al ., 2013). However, some studies have investigated whether uncertainty is an integral part of the formation of internal hazards. Such as, mistakes are the shape of internal hazards that disturb behavior in uncertain methods, and so, can replace and people in threats. (Hajcak, 2012; Weinberg et al., in press).and have been discussed to proposed the access of new anxiety problems (Meyer, Hajcak, Torpey-Newman, Kujawa \& Klein, 2015).

Eichhorn (2014) construed that the effects of unemployment on life satisfaction is moderated due to economic and demographic national-level, but not by unemployment benefits. Oshio, Umeda, and Fujii (2013) investigated how life satisfaction and self-rated health can associate with lifetime change in income and consequently, life satisfaction also changes due to increase or decrease in average income. Lindstroma and Rosvalla (2016) found that a low level of trust is strongly associated with economic stress in childhood and adulthood respectively. Reeskens and Vandecasteele (2017) investigated that economic hardship is negatively related to the well-being of employees.

Catalano et al., (2011) stated that the risk of subjective and behavioral distress is high due to bad economic performance. Fiksenbaum, Marjanovic, and Greenglass (2017) found that economic hardship was positively related to life satisfaction. McEvoy and Mahoney (2011) stated that prospective intolerance of uncertainty examines anxiety, psychological decline and the advice to do something in respect of unpredictability. Greater prospective intolerance of uncertainty has been specifically linked with morbid hardships and examines behaviors. Buhr and Dugas (2002) found that individual's high in IU practice the feasible existence of future negative circumstances as threatful believe that unpredictability is negative, effects adversely on an individual, and must be ignored, and have hardships programming well in unpredictable conditions.

Reuman, Jacoby, Fabricant, Herring, and Abramowitz (2015) found that uncertainty increased anxiety is significantly and wish to perform the low level of threat in safety behavior, but not in high levels of threat. Tanovic, Gee, and Joormann (2018) revealed that disturbance leads to uncertainty, threat, and incentives 
linked with intolerance of uncertainty that may create risk for the development of psychophysiological factors. Jackson, Nelson, and Hajcak (2016) revealed that prospective anxiety (cognitive distress) was significantly related to larger error-related brain activity and slower response time. Osmanağaoğlu, Creswell, and Dodd (2018) stated that there is a significant relationship among intolerance of uncertainty and both anxiety and worry in young individual's. Boelen, Reijntjes, and Smid (2016) stated that prospective anxiety was negatively related to symptom level of PTSD and depression.

Oglesby and Schmidt (2017) revealed that intolerance of uncertainty was linked with the high state of prospective anxiety when things are made uncertain. Carleton, Duranceau, Shulman, Zerff, Gonzales, and Mishra (2016) found that higher intolerance of uncertainty is linked with greater risk-averse behavior. Flores, Lopez, Vervliet, and Cobos (2018) investigated that prospective intolerance of uncertainty might be a vulnerability element for excessive and inflexible avoidance behavior which is significantly related to psychological distress. Counsel, Furtado, Iorio, Anand, Canzonieri, Fine and Katzman (2017) found that factors of intolerance of uncertainty linked with avoiding uncertainty are significantly related to social anxiety distress, generalized anxiety.

Talkovsky and Norton (2016) stated that prospective anxiety was not associated with time to predicted reduction in anxiety symptoms. Allan, Cooper, Oglesby, Short, Saulnier, and Schmidt (2017) stated that lower-order dimensions of anxiety sensitivity and intolerance of uncertainty show high specific and low transdiagnostic linkage with social anxiety and depression. Tang and Chan (2017) stated that life satisfaction was negatively related to perceived stress. Life satisfaction may be improved by avoidance in perceived stress in youngsters. Khamisa, Peltzer, IIic and Oldenburg (2017) revealed that personal stress is a good indicator of burnout and general health than job satisfaction, these are best predicted by work stress.

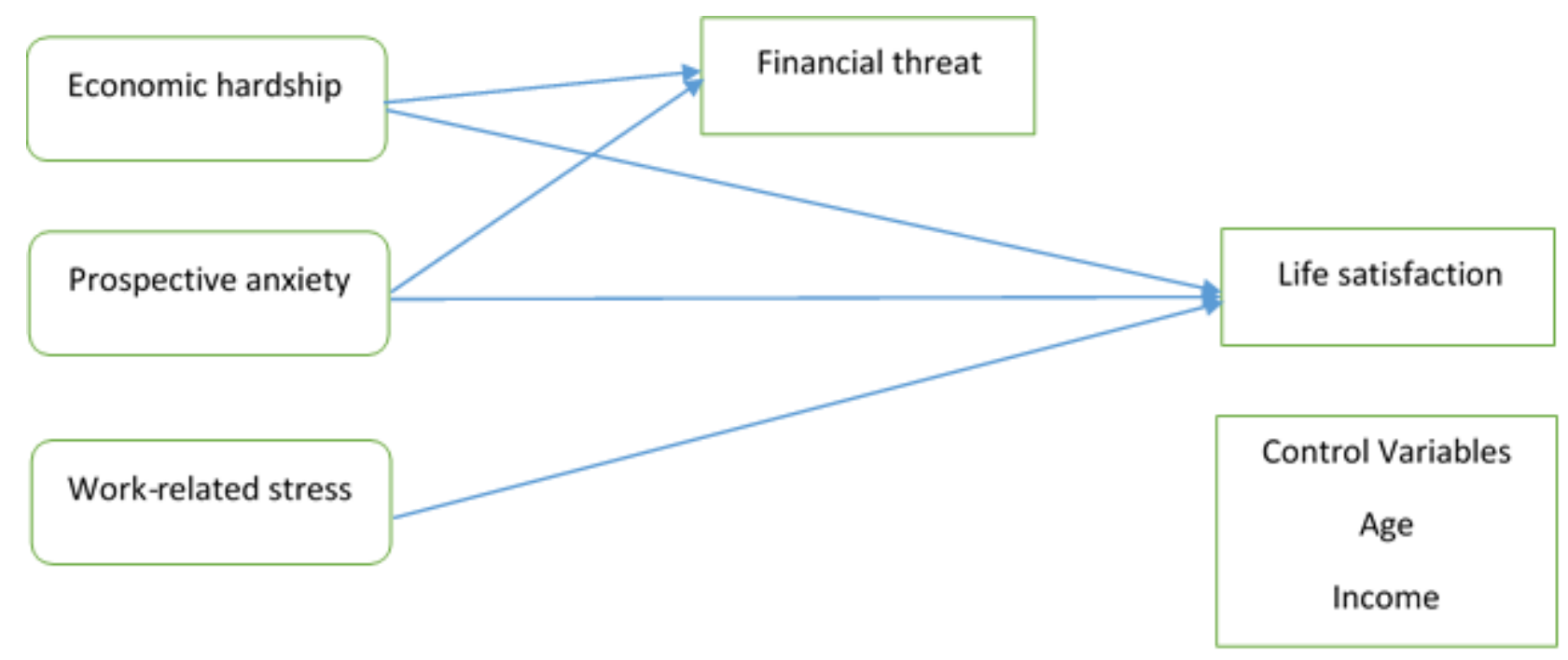

Figure 1-Research model

\section{Hypotheses}

On the base of literature review, we posit the following hypotheses:

1. Prospective anxiety is a negative impact on life satisfaction 
2. Work-related stress is a negative impact on life satisfaction.

3. Economic hardship is a negative impact on life satisfaction.

4. Prospective anxiety is positively related to the financial threat.

5. Economic hardship is positively related to the financial threat

6. The financial threat is negatively related to life satisfaction.

7. Financial threat mediates the relationship among economic hardship, prospective anxiety, and life satisfaction.

7a. Financial threat mediates the relationship between prospective anxiety and life satisfaction.

7b. Financial threat mediates the relationship between economic hardship and life satisfaction.

\section{Research Methodology}

According to Bell and Bryman (2007) to conduct the study on societal phenomenon the researcher must determine the quantitative method because it is more acceptable. The research design of this study was quantitative. Individual's employees used as a unit of analysis. The time horizon was cross-sectional because data were collected at once. The study was conducted in non-contrived settings because interference of the researcher was minimal. The target population of the study was "Non-Managerial Employees of Banks" in Lahore. The sample size was collected from item-response theory. Total 340 questionnaires were distributed among employees in which 60 were filled incomplete and remaining were lost. There were 250 respondents from the banking sector of Lahore. The non-probability convenience sampling was used due to population was unknown. Primary data was gathered through a questionnaire. The questionnaire was distributed between 18 to 40 age groups because it is observed they were faced with financial threats.

\section{Measures}

Each variable is estimated on Likert scale ranging from 1 (strongly disagree) to 5 (strong agree).

Prospective Anxiety: Prospective anxiety is related for future occasions (Greenglass et al., 2013). Prospective anxiety has measured the Intolerance of uncertainty scale (IUS) which is adopted by (Carleton et al., 2007). Prospective anxiety contains 7 items (such as; "I can't stand being taken by surprise").

Economic Hardship: Catalano, et al., (2011) stated that the risk of subjective and behavioral distress is high due to bad economic performance. Economic hardship questionnaire was adopted from Lempers et al., (1989). A 10-item consists EHQ in which estimate an individual's capability to meet their needs, not having many resources to fulfill their needs (such as; "Postpone clothing purchases").

Work-related Stress: Parker and DeCotiis (1983: 161) defined work stress as "a particular individual's awareness or feeling of personal dysfunction as a result of perceived conditions or happenings in the work settings". Work-related stress scale was adopted from Keller (1984) which contains 5-items (such as; "My work is stressful and its require efforts").

Financial Threat: Greenglass (2017) stated that frightful anxious unpredictability with respect to one's present and prospective financial circumstances. Financial threat scale was adopted from Marjanovic et al., (2013) contains 5-items (such as; "I feel uncertain").

Life Satisfaction: Life satisfaction is referred as anyone determination of life as an entire, as opposed to the sentiments and feelings that are experienced at that time (Diener, Emmons, Larsen \& Griffin, 1985). Life 
satisfaction scale was adopted by Diener et al., (1985). This scale was used to measure an individual's overall satisfaction with life contains 5-items to measure satisfaction level (such as; "I am satisfied with my life").

Control variables: Age and income were used as control variables.

\section{Results}

The data was analyzed after entering into SPSS and AMOS. Various steps were followed for descriptive and inferential analysis.

\section{Demographic Profile of Respondents}

The total sample size of the study was 250 respondents of which 151 were male showing 60.4 percentage and 99 were females (only 39.6 percentage). Data were collected from the specific age group (18-40) of the respondents. Because they were mostly faced financial circumstances. 73 respondents were aged from 18-25 years, 97 were from 25-32 and 80 were from 32-40. Sample shows that 133 respondents were satisfied with their jobs showing 53.2 percentage and 117 were not satisfied showing 46.8 percentage.

Table 1 - Correlation matrix

\begin{tabular}{llllll}
\hline Variables & $\mathbf{1}$ & $\mathbf{2}$ & $\mathbf{3}$ & $\mathbf{4}$ & $\mathbf{5}$ \\
\hline Financial Threat & .77 & & & & \\
Economic hardship & $.162^{*}$ & .75 & & & \\
Work-related stress & -.112 & $-.325^{* *}$ & .81 & & \\
Life satisfaction & $-.218^{* *}$ & $.149^{*}$ & $-.411^{* *}$ & .78 & $.306^{* *}$ \\
Prospective anxiety & $.348^{* *}$ & .216 & $.308^{* *}$ & -.71 \\
Mean & 2.583 & 2.232 & 2.696 & 4.199 & 2.912 \\
St. deviation & .626 & .420 & .438 & .589 & .456 \\
\hline
\end{tabular}

**. Correlation is significant at the 0.01 level (2-tailed)

*. Correlation is significant at the 0.05 level (2-tailed)

In this table, reliability is shown diagonally.

Above table shows that financial threat is significantly related with Economic Hardship at $r=.162$ with the level of 0.05. Financial Threat is also negatively significantly related to Life Satisfaction at $r=-.218$ with the level of 0.01 . Further, Financial threat is significantly related with Prospective Anxiety at r .348 with the level of 0.01 .

Economic hardship is negatively significant related to Work-related stress at $r=-.325$ with the level of 0.01 . Economic hardship is positively related to life Satisfaction at $r=.149$ with the level of 0.05 .

Moreover, work-related stress is negatively related to Life Satisfaction with $r=-.411$ at the level of 0.01 . So, Work-related stress is significantly related with Prospective Anxiety with $r=.306$ at the level of 0.01 .

Further, Life Satisfaction is negatively related with Prospective Anxiety with $r=-.308$ at the level of 0.01.

\section{Inferential Statistics}

Before data analysis, we checked data for normality test, homoscedasticity, multicollinearity, missing values and met all multivariate assumptions. Structural equation model was tested by two steps. Firstly, we make the Measurement Model (MM) for checking model good fit, then we ran data on SEM. The proposed structural equation model was tested using AMOS 23.0 with maximum likelihood estimation. According to Kelloway (1998) minimum, two variables were used as a latent variable. The latent variable was created for prospective 
anxiety, economic hardship and work-related stress, financial threat, and life satisfaction. All variables were imputed as a manifest variable.

Model fit was checked by tested different fit statistics (i.e. Comparative Fit Index (CFI), root mean square error of approximation (RMSEA), the goodness of fit index (GFI). The fitness of proposed model was acceptable $\mathrm{CFI}=.880 \mathrm{GFI}=.911, \mathrm{RMSEA}=.073$ after modification of indices which shows results according to threshold and model was considered fit as suggested by (Hu \& Bentler, 1999).

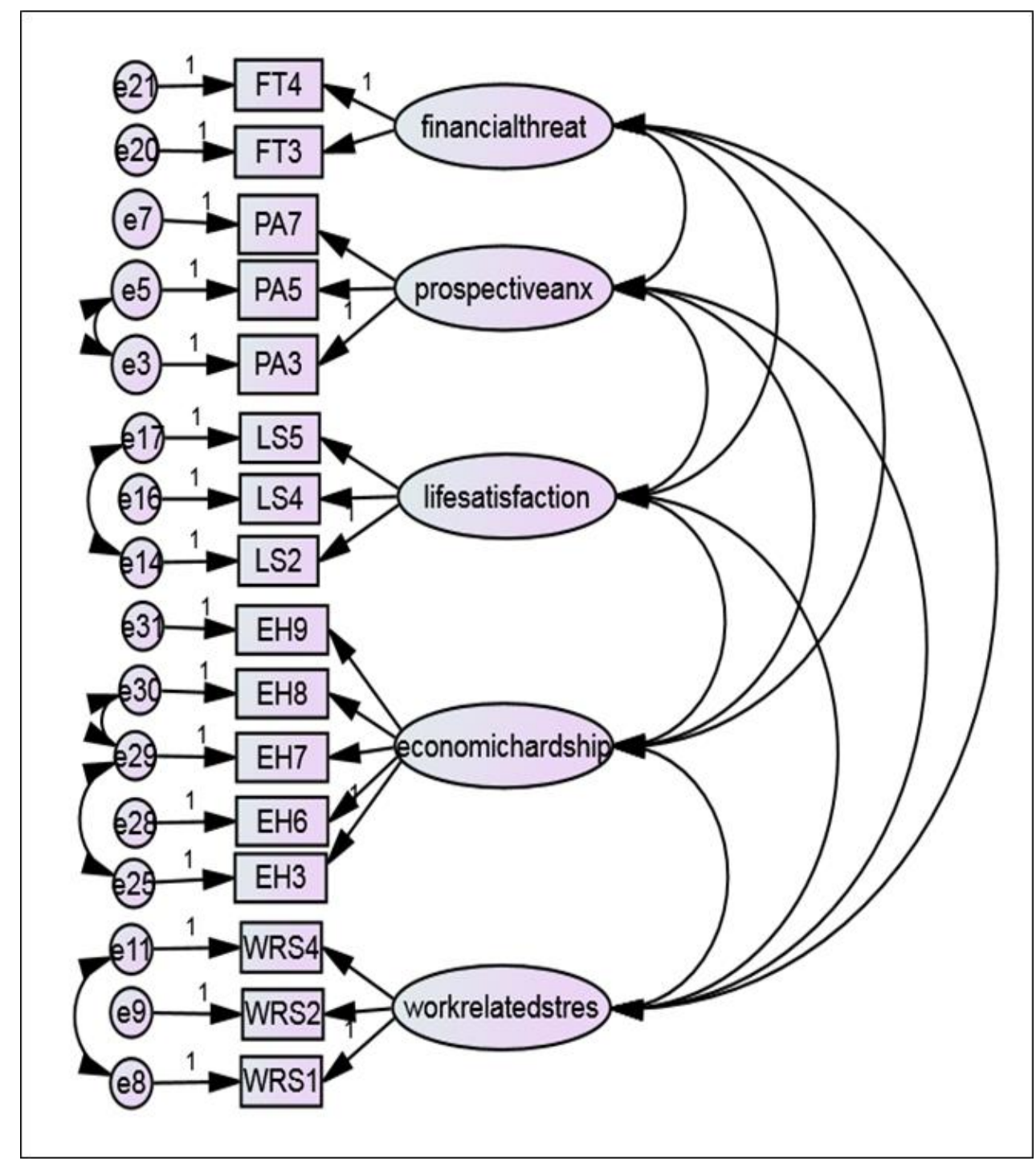

Figure 1: Measurement Model

Table 2 - Standardized Regression Weights

\begin{tabular}{lllll}
\hline Variable & & & Estimate & P value \\
\hline PA3 & $<---$ & prospectiveanx & .395 & 0.001 \\
PA5 & $<--$ & prospectiveanx & .589 & 0.001 \\
WRS1 & $<---$ & workrelatedstres & .894 & 0.001 \\
WRS2 & $<---$ & workrelatedstres & .395 & 0.001 \\
\hline
\end{tabular}




\begin{tabular}{lllll}
\hline WRS4 & $<---$ & workrelatedstres & .631 & 0.001 \\
LS2 & $<---$ & lifesatisfaction & .692 & 0.001 \\
LS4 & $<---$ & lifesatisfaction & .687 & 0.001 \\
LS5 & $<---$ & lifesatisfaction & .538 & 0.001 \\
FT3 & $<---$ & financialthreat & .644 & 0.001 \\
FT4 & $<---$ & financialthreat & .965 & 0.001 \\
EH6 & $<---$ & economichardship & .764 & 0.001 \\
EH7 & $<---$ & economichardship & .584 & 0.001 \\
EH8 & $<---$ & economichardship & .666 & 0.001 \\
EH9 & $<---$ & economichardship & .665 & 0.001 \\
PA7 & $<---$ & prospectiveanx & .601 & 0.001 \\
EH3 & $<---$ & economichardship & .468 & 0.001 \\
\hline
\end{tabular}

Factor loading of some items were less than .3. So, researcher deleted those items for the model good fitness.

\section{Structural Equation Model}

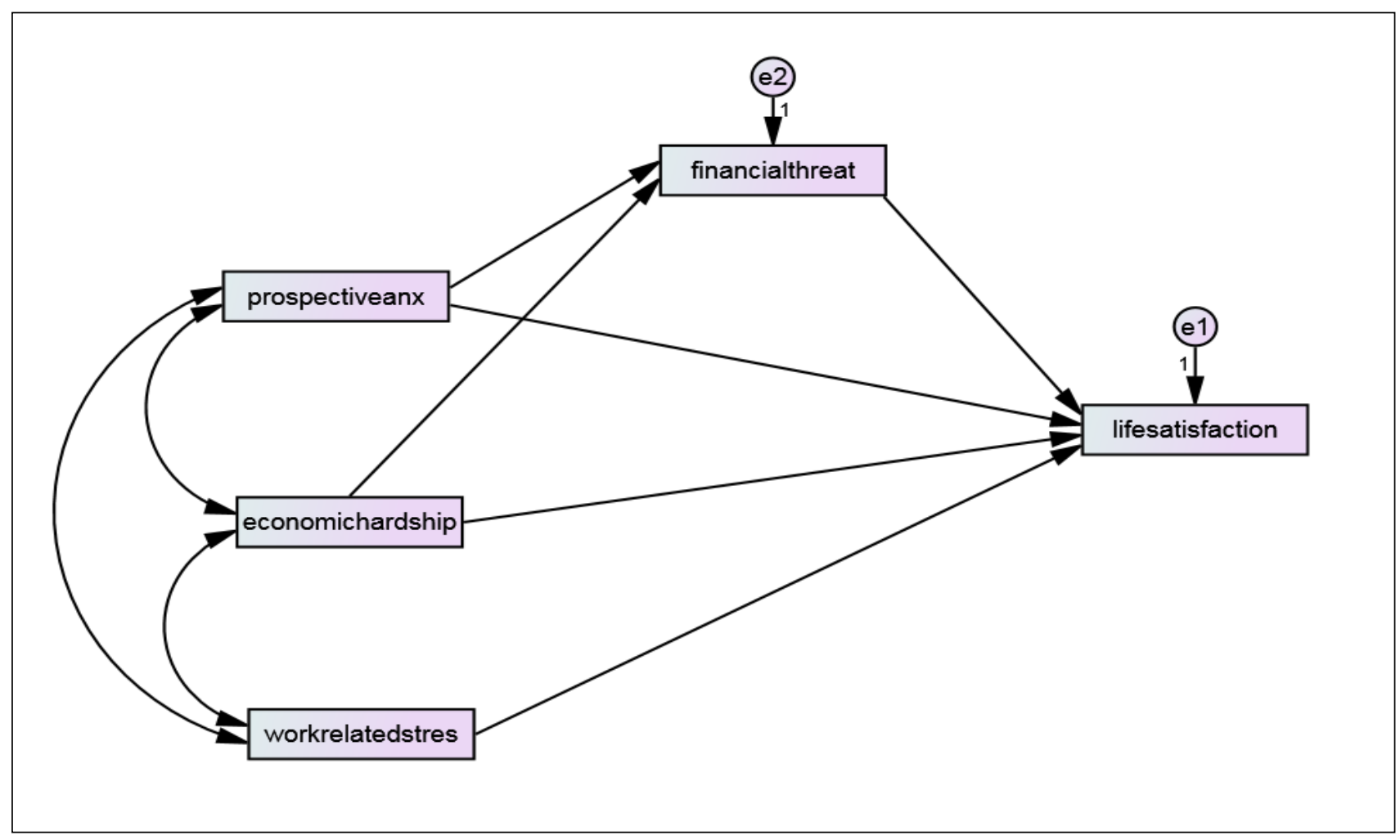

Figure 2 - Structural Equation Model

Table 3 - Standardized Regression Weights

\begin{tabular}{lllll}
\hline Variables & & & Estimate & P value \\
\hline financialthreat & $<---$ & prospectiveanx & .287 & 0.001 \\
financialthreat & $<---$ & economichardship & .450 & 0.001 \\
lifesatisfaction & $<---$ & prospectiveanx & -.640 & 0.001 \\
lifesatisfaction & $<---$ & economichardship & -.080 & 0.028 \\
lifesatisfaction & $<---$ & financialthreat & -.179 & 0.001 \\
lifesatisfaction & $<---$ & workrelatedstres & -.348 & 0.001 \\
\hline
\end{tabular}


Model fit was checked by tested different fit statistics (i.e. Comparative Fit Index (CFI), root mean square error of approximation (RMSEA), the goodness of fit index (GFI). The fitness of the proposed model was acceptable $\mathrm{CFI}=1.000, \mathrm{GFI}=1.000, \mathrm{RMSEA}=.000$ which shows model was exceptionally fit.

Examination of the standardized parameter estimates was fully supported H1. That was, prospective anxiety was a negative impact on life satisfaction. $\mathrm{H} 2$ was fully supported that work-related stress has a negative impact on life satisfaction. In supporting $\mathrm{H} 3$, economic hardship has a negative impact on life satisfaction. Supporting H4, that prospective anxiety has a positive impact on the financial threat. In supporting H5, economic hardship has a positive impact on the financial threat. Supporting H6, the financial threat has also a positive impact on life satisfaction.

Table 4 -

\begin{tabular}{|c|c|c|c|c|}
\hline Variables & $\begin{array}{l}\text { Direct } \\
\text { W/O Med }\end{array}$ & $\begin{array}{l}\text { Direct } \\
\text { W/Med }\end{array}$ & Indirect & Results \\
\hline Prospectiveanx $\rightarrow$ financialthreat $\rightarrow$ lifesatisfaction & $1.047 * * *$ & $.640^{* * *}$ & $.051 * * *$ & Partial \\
\hline Economichardship $\rightarrow$ financialthreat $\rightarrow$ lifesatisfaction & $.137 * * *$ & $.080 * * *$ & $.080 * * *$ & Partial \\
\hline
\end{tabular}

Bootstrapping techniques was used for mediation analysis. H7 was financial threat mediates the relationship between prospective anxiety, economic hardship, and life satisfaction. In supporting $\mathrm{H} 7 \mathrm{a}$, results show that financial threat mediates the relationship between prospective anxiety and life satisfaction $(\beta=.051 ; \mathrm{p}=$ 0.001). Supporting $\mathrm{H} 7 \mathrm{~b}$, results indicate that financial threat mediates the relationship between economic hardship and life satisfaction $(\beta=.080 ; \mathrm{p}=0.001)$.

\section{Discussion}

The economic crises of 2008 have a significant impact on employment trends as well as psychological prosperity of many individuals (Fiksenbaum, Marjanovic \& Greenglass, 2017). According to Bartholomae and Fox (2010), individuals not only concern about the economy but they also feel insecure about their employment. Pakistan is a growing economy in South Asia. The unemployment rate in Pakistan was $5.9 \%$ in 2017 and is growing gradually. Still, there is an issue of unemployment in Pakistan and the current rate of unemployment is $5.9 \%$ which is constant. So, economic hardship, anxiety, and stress are important features and are likely to have long-lasting consequences for many individuals.

Being unemployed, stressful working conditions and anxiety make individual's weaker after the recession. According to several studies for example (Dugas et al., 2004 ; Greenglass et al., 2013)prospective anxiety has an influence on employees life satisfaction and a study by Fiksenbaum, Marjanovic and Greenglass (2017) supported the findings as it was found that prospective anxiety is related negatively to life satisfaction ( $\beta=$ $.640 ; \mathrm{p}=0.001)$. Fears are one of the mostly used motivators to get individual for help because more fear leads to dysfunctional anxiety (Bagozzi \& Moore, 1994; Higbee, 1969). Also a number of studies (Catalano et al., 2011; Roelfs et al., 2011; Greenglass et al., 2013) show that when employees perceive that predictors for risk of not paying utility bills on time, lower level of education, lower satisfaction with housing condition, exposure to more stress on employees and dissatisfaction of life. The findings that economic hardship is related negatively to life satisfaction $(B=-.080 ; \mathrm{p}=0.001)$ is consistent with a study concluded by Fiksenbaum, Marjanovic, and Greenglass (2017).

Many studies (Lazarus \& Folkman, 1984; Fredrickson, 2001, 2004; Abolghasemi \& Varaniyab, 2010; Hamarat et al., 2001) also show that work-related stress has impact on life satisfaction and a study by (Civitci, 2015) supported the findings as it was found that work-related stress is negatively related with life satisfaction $(\beta=$ -.348, $\mathrm{p}=$ 0.001). In this context, when employees are forced to obey all rules and regulations in the organization then employees perceive that there is no fair environment inside the organization that it will 
cause an adverse effect at the workplace which is linked with work-related stress and their satisfaction of life. Given that when employees feel uncertainty about their repayment of loans can become an individual's more stressful and challenging. Greenglass et al. (2013) revealed the strong linkage between prospective anxiety and financial threat and study by Fiksenbaum, Marjanovic, and Greenglass (2017) supported the findings that prospective anxiety is related positively with financial threat $(B=.287, \mathrm{p}=0.001)$.

Being unemployed, stressful work situation, facing debt and financial threat make employees weaker. Marjanovic et al., (2015) also construed strong relationship between economic hardship and financial threat but a study by Fiksenbaum, Marjanovic, and Greenglass (2017) supported the findings that economic hardship has a positive impact on financial threat $(\beta=.450, \mathrm{p}=0.001)$. Due to the financial threat, employees feel threatened and their motivation level decreased which could affect their lives. Greenglass and Mara (2012) revealed strong association among financial threat and life satisfaction and previous study supported the findings financial threat is negatively related with life satisfaction $(\beta=-.179, p=0.001)$ by (Fiksenbaum, Marjanovic and Greenglass, 2017).

According to Lazarus and Folkman (1984) assessment of stressors, the financial threat was a mediator of psychological distress. Fiksenbaum, Marjanovic, and Greenglass (2017) reported mediation through financial threat among prospective anxiety and life satisfaction and study by (Mendoza, 2011) supported the findings that financial threat mediates the relationship between anxiety and life satisfaction $(B=-.051, p=0.001)$. By identifying the mediational effect of financial threat, proactive strategies are used that can mitigate the effects of anxiety on life satisfaction. In previous studies, there was no evidence found about the mediational effect of financial threat among work stress and life satisfaction. According to previous studies, researchers identified financial distress is a powerful mediator between economic hardship and life satisfaction (Marjanovic, Greenglass, Fiksenbaum \& Bell, 2013; Marjanovic et al., 2015). So, the study supported by (Fiksenbaum, Marjanovic, Greenglass and Garcia-Santos, 2017) financial threat mediates the relationship among economic hardship and life satisfaction $(\beta=-.080, \mathrm{p}=0.001)$. Employees who feel more threatened by their economic condition are less satisfied with their life.

\section{Policy Implications}

There are much practical and policy recommendation of this research. The current study facilitates the researcher, managers, and government to know the level of financial threat among employees. It can also help managers to understand the insight of employee adverse financial decision making. Managers also make guidelines which may minimize all the consequences of psychological distress. It is also helpful for the government to make policies in such a way that help the individuals to overcome the negative consequences of unemployment. Because, nowadays, young individuals are facing an unequal high level of joblessness and being unemployed that can have an unfavorable effect on employment chances and prospective outcomes. It also helps in identifying methods to reduce anxiety, stress and economic hardship. Because it is said to be that money can help to improve an individual's financial situation with respect to enhance their physical and emotional prosperity.

\section{Limitations and Future Recommendation:}

This study was cross-sectional so, in future, it can be a longitudinal study. Our study depends on self-reported data, which cause biases in results. Financial literacy, personality traits were not studied here. Future research involved that it can be correlated financial behavior like as cash flow, management, credit management, saving and investing behaviors. 


\section{References}

Abolghasemi, A., \& Varaniyab, S. T. (2010). Resilience and perceived stress: predictors of life satisfaction in the students of success and failure. Procedia-Social and Behavioral Sciences, 5, 748-752.

Allan, N. P., Cooper, D., Oglesby, M. E., Short, N. A., Saulnier, K. G., \& Schmidt, N. B. (2017). Lowerorder anxiety sensitivity and intolerance of uncertainty dimensions operate as specific vulnerabilities for social anxiety and depression within a hierarchical model. Journal of anxiety disorders.

Ayala-Nunes, L., Jiménez, L., Jesus, S., \& Hidalgo, V. (2018). Social Support, Economic Hardship, and Psychological Distress in Spanish and Portuguese At-Risk Families. Journal of Child and Family Studies, 1-11.

Bagozzi, R. P., \& Moore, D. J. (1994). Public service advertisements: Emotions and empathy guide prosocial behavior. The Journal of Marketing, 56-70.

Bartholomae, S., \& Fox, J. (2010). Economic stress and families. Families and change: coping with stressful events and transitions, 185-210.

Bell, E., \& Bryman, A. (2007). The ethics of management research: an exploratory content analysis. British Journal of Management, 18(1), 63-77.

Bird, B., \& Schjoedt, L. (2009). Entrepreneurial behavior: Its nature, scope, recent research, and agenda for future research. In Understanding the entrepreneurial mind (pp. 327-358). Springer, New York, NY.

BOARDMAN, R. M. (1985). The relationship between life satisfaction and job satisfaction among teachers in four Midwestern states.

Boelen, P. A., Reijntjes, A., \& Smid, G. E. (2016). Concurrent and prospective associations of intolerance of uncertainty with symptoms of prolonged grief, posttraumatic stress, and depression after bereavement. Journal of anxiety disorders, 41, 65-72.

Buhr, K., \& Dugas, M. J. (2002). The intolerance of uncertainty scale: Psychometric properties of the English version. Behavior research and therapy, 40(8), 931-945.

Carleton, R. N., Duranceau, S., Shulman, E. P., Zerff, M., Gonzales, J., \& Mishra, S. (2016). Selfreported intolerance of uncertainty and behavioral decisions. Journal of behavior therapy and experimental psychiatry, 51, 58-65.

Carleton, R. N., Norton, M. P. J., \& Asmundson, G. J. (2007). Fearing the unknown: A short version of the Intolerance of Uncertainty Scale. Journal of anxiety disorders, 21(1), 105-117.

Catalano, R., Goldman-Mellor, S., Saxton, K., Margerison-Zilko, C., Subbaraman, M., LeWinn, K., \& Anderson, E. (2011). The health effects of economic decline. Annual review of public health, 32, 431-450.

Catalano, R., Goldman-Mellor, S., Saxton, K., Margerison-Zilko, C., Subbaraman, M., LeWinn, K., \& Anderson, E. (2011). The health effects of economic decline. Annual review of public health, 32, 431-450.

Civitci, A. (2015). Perceived stress and life satisfaction in college students: Belonging and extracurricular participation as moderators. Procedia-Social and Behavioral Sciences, 205, 271-281.

Counsell, A., Furtado, M., Iorio, C., Anand, L., Canzonieri, A., Fine, A. \& Katzman, M. A. (2017). Intolerance of uncertainty, social anxiety, and generalized anxiety: Differences by diagnosis and symptoms. Psychiatry research, 252, 63-69.

Diener, E. D., Emmons, R. A., Larsen, R. J., \& Griffin, S. (1985). The satisfaction with life scale. Journal of personality assessment, 49(1), 71-75. 
Dugas, M. J., Buhr, K., \& Ladouceur, R. (2004). The Role of Intolerance of Uncertainty in Etiology and Maintenance.

Eichhorn, J. (2014). The (non-) effect of unemployment benefits: Variations in the effect of unemployment on life-satisfaction between EU countries. Social indicators research, 119(1), 389404.

Fiksenbaum, L., Marjanovic, Z., \& Greenglass, E. (2017). Financial threat and individuals' willingness to change financial behavior. Review of Behavioral Finance, 9(2), 128-147.

Fiksenbaum, L., Marjanovic, Z., \& Greenglass, E. (2017). Financial threat and individuals' willingness to change financial behavior. Review of Behavioral Finance, 9(2), 128-147.

Flores, A., López, F. J., Vervliet, B., \& Cobos, P. L. (2018). Intolerance of uncertainty as a vulnerability factor for excessive and inflexible avoidance behavior. Behavior research and therapy.

Frank, B., \& Gilbreth, L. M. (1918). The Engineer, the Cripple, and the New Education. American Society of Mechanical Engineers Journal, 40(52), 4-7.

Fredrickson, B. L. (2001). The role of positive emotions in positive psychology: The broaden-and-build theory of positive emotions. American Psychologist, 56(3), 218.

Fredrickson, B. L. (2004). The broaden-and-build theory of positive emotions. Philosophical Transactions of the Royal Society B: Biological Sciences, 359(1449), 1367.

Godard, J. (2004). A critical assessment of the high-performance paradigm. British journal of industrial relations, 42(2), 349-378.

Greenglass, E., \& Mara, C. (2012). Self-efficacy as a psychological resource in difficult economic times. Stress and anxiety: Application to economic hardship, occupational demands, and developmental challenges, 29-38.

Greenglass, E., Marjanovic, Z., \& Fiksenbaum, L. (2013). The impact of the recession and its aftermath on individual health and well-being. The psychology of the recession on the workplace, 42-58.

Hamarat, Dennis Thompson, Karen M. Zabrucky, Don Steele, Kenneth B. Matheny, Ferda Aysan, E. (2001). Perceived stress and coping resource availability as predictors of life satisfaction in young, middle-aged, and older adults. Experimental Aging Research, 27(2), 181-196.

Higbee, K. L. (1969). Fifteen years of fear arousal: research on threat appeals: 1953-1968. Psychological Bulletin, 72(6), 426.

Hu, L. T., \& Bentler, P. M. (1999). Cutoff criteria for fit indexes in covariance structure analysis: Conventional criteria versus new alternatives. Structural equation modeling: a multidisciplinary journal, 6(1), 1-55.

Hwang, M. G., \& Kim, E. J. (2008). The effect of subjective quality of life and self-esteem on suicide ideation among older adults: Focused on the mediating effect of depression. Journal of the Korean Gerontological society, 28(4), 865-885.

Jackson, F., Nelson, B. D., \& Hajcak, G. (2016). The uncertainty of errors: intolerance of uncertainty is associated with error-related brain activity. Biological psychology, 113, 52-58.

Kahneman, D., \& Deaton, A. (2010). High income improves evaluation of life but not emotional wellbeing. Proceedings of the national academy of sciences, 107(38), 16489-16493.

Keller, D. (1984). Humor as therapy. Med-Psych Publications.

Kelloway, E. K. (1998). Using LISREL for structural equation modeling: A researcher's guide. Sage.

Khamisa, N., Peltzer, K., Ilic, D., \& Oldenburg, B. (2017). Effect of personal and work stress on burnout, job satisfaction and general health of hospital nurses in South Africa. Health SA Gesondheid, 22, 252-258.

Lazarus, R. S., \& Folkman, S. (1984). Coping and adaptation. The handbook of behavioral medicine, 282325. 
Lease, S. H. (1998). Annual review, 1993-1997: Work attitudes and outcomes. Journal of Vocational Behavior, 53(2), 154-183.

Lempers, J. D., Clark-Lempers, D., \& Simons, R. L. (1989). Economic hardship, parenting, and distress in adolescence. Child development, 25-39.

Lindström, M., \& Rosvall, M. (2016). Life course perspectives on economic stress and generalized trust in other people. The Social Science Journal, 53(1), 7-13

Locke, E. A. (2009). Handbook of Principles of Organizational Behavior: Indispensable Knowledge for Evidence-Based Management, Second.

Marjanovic, Z., Greenglass, E. R., Fiksenbaum, L., \& Bell, C. M. (2013). Psychometric evaluation of the Financial Threat Scale (FTS) in the context of the great recession. Journal of Economic Psychology, 36, 1-10.

Marjanovic, Z., Greenglass, E. R., Fiksenbaum, L., De Witte, H., Garcia-Santos, F., Buchwald, P., ... \& Mañas, M. A. (2015). Evaluation of the Financial Threat Scale (FTS) in four European, nonstudent samples. Journal of Behavioral and Experimental Economics, 55, 72-80.

McEvoy, P. M., \& Mahoney, A. E. (2011). Achieving certainty about the structure of intolerance of uncertainty in a treatment-seeking sample with anxiety and depression. Journal of Anxiety Disorders, 25(1), 112-122.

Mendoza, M. E. G., \& Bianchi, J. (2011). Overborrowing, financial crises, and 'macro-prudential'policy? (No. 11-24). International Monetary Fund.

Miles, M. M., Szwedo, D. E., \& Allen, J. P. (2018). Learning to cope with anxiety: Long-term links from adolescence to adult career satisfaction. Journal of Adolescence, 64, 1-12.

Millán, J. M., Hessels, J., Thurik, R., \& Aguado, R. (2013). Determinants of job satisfaction: a European comparison of self-employed and paid employees. Small business economics, 40(3), 651-670.

Niharika, U. V. Life Satisfaction among Bank Employees. Work, 855, 1.

Oglesby, M. E., \& Schmidt, N. B. (2017). The Role of Threat Level and Intolerance of Uncertainty (IU) in Anxiety: An Experimental Test of IU Theory. Behavior therapy, 48(4), 427-434.

Oshio, T., Umeda, M., \& Fujii, M. (2013). The association of life satisfaction and self-rated health with income dynamics among male employees in Japan. Japan and the World Economy, 28, 143-150.

Osmanağaoğlu, N., Creswell, C., \& Dodd, H. F. (2018). Intolerance of Uncertainty, anxiety, and worry in children and adolescents: A meta-analysis. Journal of affective disorders, 225, 80-90.

Parker, D. F., \& DeCotiis, T. A. (1983). Organizational determinants of job stress. Organizational behavior and human performance, 32(2), 160-177.

Reeskens, T., \& Vandecasteele, L. (2017). Economic hardship and well-being: Examining the relative role of individual resources and welfare state effort in resilience against economic hardship. Journal of Happiness Studies, 18(1), 41-62

Reuman, L., Jacoby, R. J., Fabricant, L. E., Herring, B., \& Abramowitz, J. S. (2015). Uncertainty as an anxiety cue at high and low levels of threat. Journal of behavior therapy and experimental psychiatry, 47, 111-119.

Roelfs, D. J., Shor, E., Davidson, K. W., \& Schwartz, J. E. (2011). Losing life and livelihood: a systematic review and meta-analysis of unemployment and all-cause mortality. Social science \& medicine, 72(6), 840-854.

Schmitt, M. T., Aknin, L. B., Axsen, J., \& Shwom, R. L. (2018). Unpacking the relationships between pro-environmental behavior, life satisfaction, and perceived an ecological threat. Ecological Economics, 143, 130-140.

Spector, P. E. (1997). Job satisfaction: Application, assessment, causes, and consequences (Vol. 3). Sage publications. 
Swami, V., Chamorro-Premuzic, T., Sinniah, D., Maniam, T., Kannan, K., Stanistreet, D., \& Furnham, A. (2007). General health mediates the relationship between loneliness, life satisfaction, and depression. Social psychiatry and psychiatric epidemiology, 42(2), 161-166.-166.

Talkovsky, A. M., \& Norton, P. J. (2016). Intolerance of uncertainty and transdiagnostic group cognitive behavioral therapy for anxiety. Journal of anxiety disorders, 41, 108-114.

Tang, K. N., \& Chan, C. S. (2017). Life satisfaction and perceived stress among young offenders in a residential therapeutic community: Latent change score analysis. Journal of Adolescence, 57, 4253.

Tanovic, E., Gee, D. G., \& Joormann, J. (2018). Intolerance of uncertainty: Neural and psychophysiological correlates of the perception of uncertainty as threatening. Clinical psychology review. 